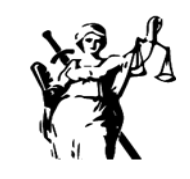

JUSTICIA

ISSN impreso 0124-7441
ISSN digital 2590-4566

\title{
Lo Sagrado en la Política: cuestionando la teoría de la diferenciación de las esferas*
}

\section{The Sacred in Politics: questioning the theory of the differentiation of the spheres}

\author{
(iD) \\ Jean Paul Sarrazin \\ Universidad de Antioquia, Colombia Colombia \\ Jean.sarrazin@udea.edu.co \\ Recibido: 07 de febrero de 2020/ Aceptado: 11 de julio de 2020 \\ https://doi.org/10.17081/just.25.38.4439 \\ Resumen
}

Objetivo: En este artículo se argumenta que la teoría clásica sobre la diferenciación de la esfera religiosa y la consecuente secularización de la modernidad ha dado pie a interpretaciones y generalizaciones erradas, puesto que, en la complejidad de los procesos socio-históricos, no existen fronteras claramente identificables que permitan separar analíticamente lo político de lo religioso. Método: La crítica aquí expuesta se basa en un análisis segmentado de la teoría de la secularización y en una revisión del concepto de "religión" como categoría analítica frecuentemente usada en las ciencias sociales. Resultados: Se sostiene que, si la religión se concibe como una esfera separada (diferenciación) que ha perdido su poder y tiende a desaparecer (secularización), ello no solo es muy cuestionable desde el punto de vista empírico, sino que es absolutamente dependiente de lo que se entiende por el concepto de "religión", una precisión que no se suele hacer en las ciencias sociales. Conclusiones: Se concluye que las esferas se diferencian únicamente en su dimensión institucional, y que los aportes de Émile Durkheim son de gran valía para identificar lo sagrado en la política moderna, demostrando así que lo religioso está presente incluso en las instituciones seculares. Ello se demuestra mediante en caso de la sacralización del individuo en las democracias liberales contemporáneas.

Palabras claVe: émile durkheim, secularización, diferenciación, política, religión, modernidad liberal.

\begin{abstract}
Objective: This article argues that the classical theory on the differentiation of the religious sphere and the following secularization of modernity has provoked erroneous interpretations and generalizations, since, in the complexity of the socio-historical processes, there are no clearly identifiable boundaries that would allow to analytically separate the political from the religious. Method: The critique presented here is based on a segmented analysis of secularization theory and on a revision of the concept of "religion" as an analytical category frequently used in the social sciences. Results: It is argued that, if religion is conceived as a separate sphere (differentiation) that has lost its power and tends to disappear (secularization), this is not only highly questionable from an empirical point of view, but is absolutely dependent on what is understood by the concept of "religion", a precision that is not usually made in the social sciences. Conclusions: It is concluded that the spheres differ only in their institutional dimension, and that the contributions of Émile Durkheim are of great value in identifying the sacred in modern politics, thus demonstrating that the religious is present even in secular institutions. This is demonstrated through the case of the sacralization of the individual in contemporary liberal democracies.
\end{abstract}

KEYWORDS: émile durkheim, secularization, differentiation, politics, religion, liberal modernity.

\section{Como citar:}

Sarrazin, J. P. (2020). Lo Sagrado en la Política: cuestionando la teoría de la diferenciación de las esferas. Justicia, 25(38), 163-178. https://doi.org/10.17081/just.25.38.4439

*Este artículo es producto de la primera fase (culminada) del proyecto de investigación "Religión y Pluralismo. Problemáticas contemporáneas", el cual cuenta con el apoyo de la Facultad de Ciencias Sociales y Humanas de la Universidad de Antioquia. 


\section{Introducción}

Según la teoría sociológica clásica, las sociedades modernas se caracterizan por la diferenciación y autonomización de esferas tales como la religión, la política, la economía o el arte. De acuerdo con Weber (1978), por ejemplo, esta autonomización implica que cada una de las esferas se rige de acuerdo con su propio conjunto de "valores últimos". Este proceso ha significado que, en ciertos momentos y circunstancias, las esferas pueden enfrentarse, lo cual ha sido particularmente notorio en el caso de las esferas política y religiosa (Blancarte, 2015). Esta última diferenciación ha dado lugar a un proceso de secularización que también se asume, desde la teoría, como uno de los rasgos distintivos de la modernidad (Casanova, 1994; Tschannen, 1991).

En este texto se argumenta que tal teoría de la diferenciación y la secularización ha dado pie a interpretaciones y generalizaciones erradas, puesto que, en la complejidad de los procesos socio-históricos, no existen fronteras claramente identificables que permitan separar analíticamente lo político de lo religioso. Así, se plantea un análisis crítico de dicha teoría, motivado por la necesidad de aclarar y precisar la noción de una "esfera religiosa" como algo separado y enfrentado a la política en las sociedades modernas.

A ello se llega mediante un análisis segmentado de la teoría de la secularización y una revisión del concepto de "religión" como categoría analítica frecuentemente usada en las ciencias sociales. Se argumenta entonces que, si la religión se concibe como una esfera separada (diferenciación), que además ha perdido su poder y tiende a desaparecer (secularización), ello no solo es muy cuestionable desde el punto de vista empírico, sino que es absolutamente dependiente de precisar lo que entendemos por el concepto de "religión", una precisión que no se suele hacer en las ciencias sociales.

Cabe aclarar de antemano que, al plantear aquí que lo religioso está presente en la política -planteamiento que pone en tela de juicio tanto la diferenciación como la secularización- no pretendemos limitarnos a evocar la influencia o injerencia que tienen ciertas instituciones religiosas en la política estatal (Casanova, 1994), o la participación que pueden tener dichas instituciones en las decisiones públicas bajo regímenes democráticos y pluralistas (Habermas, 2006; Mardones, 2006).

La relación entre religión y política que se presenta acá también trasciende planteamientos como los de Carl Schmitt (2000), quien señaló la importancia que han tenido la teología y las estructuras religiosas en la conformación de los conceptos jurídico-políticos y las prácticas de gobierno modernas. Para Schmitt, la religión influye en elementos centrales del ámbito político-jurídico como son la soberanía o la representación. Schmitt muestra además que las sociedades modernas, consciente o inconscientemente han hecho una analogía entre la omnipotencia de Dios y el poder soberano, o entre Cristo y su Iglesia como figuras mediadoras, y la representación política como figura de mediación entre el pueblo y el Estado (Herrero, 2017). No nos adentraremos en los argumentos de Schmitt, no por considerarlos menores, sino porque, como ya dijimos, es otro el tipo de relación entre religión y política que se presenta en este artículo.

Como ya se dijo, las reflexiones que se hagan a propósito del lugar de la religión en la sociedad dependen de lo que se entiende por "religión". Desde Marx, por ejemplo, la religión es el "opio del pueblo", un conjunto de creencias falsas e ilusorias que funcionan como una droga para paliar la miseria real en la que vive el creyente. "La miseria religiosa es, al mismo tiempo, la expresión de la miseria real y la protesta contra ella" (Marx, 2010, p. 7). Este tipo de críticas, bien conocidas desde el siglo XIX, supone que la religión es un conjunto de creencias a propósito de poderes lejanos, invisibles, misteriosos y superiores de los cuales el hombre sería absolutamente dependiente (Eliade, 1999, p. 544). Desde esa perspectiva, la religión brinda falsas esperanzas en poderes sobrenaturales que algún día vendrían a salvar al hombre de su miseria. Aunque seguramente muchas personas en el mundo creen en dichos poderes sobrenaturales, no es a ese tipo de creencias al que nos referiremos acá. 
Weber, por su parte, nunca planteó una definición de religión, sino que se dedicó a estudiar "las condiciones y efectos de un determinado tipo de acción comunitaria" (Weber, 2002, p. 328), el tipo de acción que ocurre en el marco de lo que convencional y comúnmente se entiende como "las religiones del mundo" (Weber, 1978). Para este autor, como para muchos otros, no es necesario tener una definición precisa de religión. Basta entonces con tomar lo que comúnmente se entiende por "religiones", describirlas, analizarlas, conocer sus causas y consecuencias, etc. Así, por ejemplo, Weber analizó las religiones de salvación y su ética fraternal-como es el caso del cristianismo institucionalizado que imperaba en Occidente-, afirmando que esas religiones entran en confrontación con los ordenamientos de la esfera política moderna, cuyos valores y reglas se diferencian de las primeras (Weber, 1978, p. 71-72).

Durkheim, en cambio, insiste en la necesidad de plantear una definición general de religión, más allá de las formas de acción comunitaria tradicionalmente conocidas como "religiones". Y es que, para él, "la primera gestión del sociólogo debe ser la de definir las cosas de las que trata" (Durkheim, 1997, p. 76). Veremos por qué esto es clave para sustentar la línea de argumentación del presente texto. En lo relativo a nuestro tema, para el sociólogo francés se trata de "identificar un cierto número de signos exteriores, fácilmente perceptibles, que permitan el reconocimiento de los fenómenos religiosos allá donde se encuentren" (Durkheim, 1982, p. 21). Queda entonces en evidencia que, para Durkheim, los fenómenos religiosos pueden encontrarse incluso por fuera de lo que comúnmente se conoce como las "religiones del mundo". Para el autor, como veremos, lo sagrado es un elemento esencial en la religión y no debe confundirse con la creencia en poderes invisibles o sobrenaturales. Mientras que otros aspectos como los templos y los sacerdotes serían secundarios (Durkheim, 1898, p. 11), aquel núcleo sagrado es lo que nos permite argumentar que lo religioso está presente en sujetos, instituciones, esferas o sistemas "seculares", incluyendo la "esfera política".

No se pretende con ello afirmar que la diferenciación no existe. La diferenciación funcional de la que hablara el mismo Durkheim (2001) y que autores contemporáneos como Luhmann (2009) retoman, es una evidencia que hoy en día no solo se preserva, sino que se expande a escala planetaria (Beyer, 2013). Sin embargo, cuando se habla de la religión como una esfera separada, no se han considerado las recientes transformaciones de lo religioso más allá de las religiones convencionales e institucionalizadas. No se niega entonces que haya un conjunto de religiones que cumplen funciones especializadas, poseen códigos y valores particulares, y manejan formas de comunicación propias (Luhmann, 2009). No cabe duda de que el Estado moderno administra de acuerdo con reglas establecidas que pueden diferir con respecto a las reglas de las religiones instituidas. Cada una de estas dos "esferas" posee su propia legalidad interna, define sus propias reglas y valores. Por ello, es claro que, en la modernidad, encontramos reglas jurídicas, reglas políticas, reglas religiosas, etc.

Tampoco se pretende discutir la idea según la cual la religión sería esencial para la constitución y cohesión de las sociedades modernas - una derivación del funcionalismo durkheimiano que ha sido cuestionada por autores como Niklas Luhmann-. Sin duda, la institución religiosa no es ya necesaria para mantener la integración de una sociedad (Luhmann, 2009), así como tampoco es la única fuente de sentido último para los individuos (Luhmann, 1985). Pero la presencia y el papel protagónico de lo religioso no se agota en las presunciones anteriores. El objetivo del presente texto es cuestionar las teorías de la secularización y la diferenciación en la medida en que lo religioso -en tanto que expresión de lo sagrado- influye en "esferas" supuestamente diferenciadas y seculares, como la política.

La argumentación presentada a continuación se compone de cuatro momentos. Primeramente, es necesario un breve recorrido histórico que permite notar los orígenes de la diferenciación entre la religión y las distintas esferas seculares. En un segundo momento, se abordarán los conceptos de "des-secularización" 
(Berger, 1999) y "post-secularidad" (Habermas, 2006), los cuales hacen notar las falencias de las tesis secularistas en el mundo contemporáneo, y llaman la atención sobre una situación contemporánea en la que se legitima cada vez más la presencia de la religión en la esfera política. En tercer lugar, iremos más allá de dichos conceptos para demostrar que lo religioso no se limita a una institución o "esfera", y que puede manifestarse en ámbitos "seculares" y modernos, para lo cual nos basaremos en el concepto de lo sagrado que propone Durkheim, posicionándolo como categoría analítica operacional en el estudio de las complejidades socioculturales contemporáneas. Finalmente, se provee un ejemplo de la forma en que lo sagrado hace parte fundamental de la política moderna, particularmente a través del individualismo intrínseco en las democracias liberales.

\section{Orígenes históricos de una diferenciación}

La religión como una esfera diferenciada es una construcción de Occidente cuyo nacimiento se explica al tener en cuenta la historia de Europa. En la alta edad media, la Iglesia cristiana surge como la principal institución en los territorios del antiguo imperio romano (Beyer, 1999, p. 205). En este contexto, la Iglesia -autoproclamada como "la religión"- toma total predominancia en la sociedad medioeval. En el código binario de salvación/condenación que estructura el pensamiento de aquella sociedad, la iglesia poseía los "bienes de salvación" que se hacían necesarios para los sujetos. El código moral elaborado y unificado por la Iglesia "conectaba virtualmente a toda la actividad humana social" (Beyer, 1999, p. 206). El poder de la Iglesia sobrepasaba de lejos el de cualquier otra institución política que pretendiera imponer su sistema y su "código".

Durante la alta Edad Media la separación de los dominios o esferas no existía (Casanova, 1994, p. 13). La diferenciación fue formándose después, cuando la Iglesia, es decir, la institución religiosa, entra en conflictos de interés con otros individuos y grupos que aspiraban progresivamente a tener posiciones dominantes y privilegiadas que la Iglesia había monopolizado. "Entre [los años] 1000 y 1500, por redondear fechas, se inventa en Europa un nuevo tipo de poder, alrededor de la figura del rey y del reino" (Gauchet, 2005, p. 298). En otras palabras, y de manera muy sucinta, entraron en pugna los jefes de la Iglesia con los señores y reyes de los distintos territorios que el Vaticano intentaba dominar.

Paradójicamente, el gran poder político de la Iglesia medieval fue justamente una de las condiciones previas que permitió su estrepitosa caída siglos más tarde, cuando es relegada a un sistema aparte. El monopolio político que la Iglesia se obstinaba en preservar condujo a que los sectores sociales que aspiraban a tener algún poder y no pertenecían a la rígida y excluyente estructura eclesial, tuvieran que luchar contra la Iglesia misma, buscando acabar con dicho monopolio. En la modernidad temprana, para muchos, la solución fue simplemente la de destruir completamente la Iglesia y decapitar cada uno de los integrantes del clero (por ejemplo, en la Revolución Francesa), y para otros, la alternativa que se fue dando consistió en separar la Iglesia de las decisiones políticas, relegándola a la esfera de lo "privado" o lo "espiritual" (Luckmann, 1973). Así pues, la disputa por el poder entre la Iglesia y otros sectores desencadenó el proceso que hoy llamamos "diferenciación de la religión”, proceso que, en la práctica, relega la Iglesia a una serie de funciones "religiosas" o "espirituales", mas no políticas ni económicas.

Como Casanova (1994, p. 14-15) hace notar, la diferenciación entre la religión y las demás esferas (en particular la esfera política) es una división entre aquello que pertenece y/o es dominado por la Iglesia, y aquello que pertenece y/o es dominado por sectores sociales ajenos a esa institución (es decir, "seculares", según la misma Iglesia medieval los llamó). De hecho, los sectores sociales seculares buscaron obtener -a veces con éxito- la legitimidad que la institución religiosa tenía por medio de las referencias a lo divino y lo 
sagrado. Es así que, como ejemplo de lo anterior, sabemos que los reyes pretendieron ser entronizados por Dios. Esto, sin embargo, no hacía más que agudizar la rivalidad y el conflicto entre la nobleza y la Iglesia.

La pérdida de poder de la Iglesia está relacionada con macro-procesos societales como el advenimiento del capitalismo, la formación de los Estados modernos, la revolución científica y la Reforma Protestante. Esta Reforma es quizás el factor menos mentado, pero es importante destacarlo, ya que es muy significativo que la marginalización de la religión provenga en parte de procesos propiamente religiosos. Los reformistas cristianos eran, recordémoslo, los primeros y más fervientes críticos de la Iglesia, y en su esfuerzo por "depurar" la religión cristiana favorecieron la creación de una religión altamente diferenciada. La Reforma proponía una religión netamente "espiritual", separada de la vida social "mundana" o "profana", es decir, de la vida económica, política, etc., y lejos de su forma institucionalizada (Beyer, 1999, p. 207). El papel de la Reforma fue determinante al minar la unidad, la legitimidad y el monopolio de la Iglesia católica, apostólica y Romana. En otras palabras, la Reforma contribuyó al desmoronamiento de un sistema centralizado y orgánico dominado por una Iglesia-religión, facilitando la actuación, influencia y eventual dominación de otras instituciones o estructuras societales.

Si recordamos que el cristianismo institucionalizado se autoproclama y se establece en el imaginario de Occidente como La Religión, cuando el protestantismo plantea que la verdadera religión estaba por fuera de la institución religiosa (Iglesia), lo que está planteando es -por paradójico que parezca- una religión por fuera de la religión. Es por eso que Gauchet considera el cristianismo como "la religión de la salida de la religión" (Gauchet, 2005, p. 145). El protestantismo es, en efecto, "una fuerza secularizante" (Casanova, 1994, p. 22)1 que contribuye a generar aquella idea según la cual la religión sería una cuestión "privada", ya que plantea que la relación con la divinidad debe ser individual, "directa y totalmente interior" (Gauchet, 2005, p. 95). Opera así una "legitimación del foro interno separada de la norma colectiva" (Gauchet, 2005, p. 95), todo lo cual tiene un efecto desestabilizador radical, ya que, en las sociedades anteriores al Estado, la Iglesia pretendía dictar dicha norma colectiva y organizar las relaciones sociales (Gauchet, 2005, p. 21). Por otro lado, la idea protestante de una divinidad trascendente, es decir, por fuera de este mundo, plantea que la comprensión del mundo es un asunto separado de la religión, abriendo así la puerta a la ciencia, esa otra esfera diferenciada (Gauchet, 2005, p. 92). Finalmente, al poner a la religión en el plano trascendente, más allá de este mundo, también se le aleja del poder sobre el mundo social, quedando así disponible el espacio para que otra esfera, la de la política estatal, entre a regular las relaciones humanas (Gauchet, 2005, p. 57-67).

Esta breve reseña histórica permite notar que la noción de la "religión" como una esfera diferenciada se modela entonces sobre la base de una disputa entre la Iglesia y otros sectores sociales. Luego del comienzo de su declive, la Iglesia se presenta gradualmente como un "sistema" (para ponerlo en términos luhmannianos) cuya función se limita, por decirlo de manera muy abreviada, a los aspectos "espirituales" y "privados" de las personas. Vemos así que "la religión" como un sistema diferenciado de "lo secular" es una construcción histórica particular que toma pleno sentido únicamente en la modernidad y que se basa la identificación religión-Iglesia y el conflicto de poder que surge en Europa (y los territorios colonizados por ella) entre esa religión institucionalizada y otros sectores sociales ajenos a ella, es decir, sectores que la misma Iglesia había llamado "seculares" (Casanova, 1994).

1 No sobra recordar la relación que tiene el Protestantismo con la economía capitalista, señalada por muchos autores como Weber $(1978,1999)$, aunque sobre esto no podemos ahondar en este espacio. 


\section{Más allá del ideal secularista: Des-secularización, post-secularidad y otros cuestionamientos desde la modernidad tardía y globalizada}

Más allá de la evidente diferenciación funcional entre la religión-Iglesia y otros sistemas en la modernidad, son varias las investigaciones que demuestran que, en la complejidad de nuestras realidades sociales, la identificación de una "esfera religiosa" diferenciada es un ejercicio analítico sumamente problemático, como también lo es la separación entre lo religioso y lo político.2 Asad (1993, p. 53), por ejemplo, resalta que lo político, lo jurídico, o lo económico, no están simplemente relacionados con lo religioso, sino que son inseparables de ello. Según Derrida, "sería preciso disociar los rasgos esenciales de lo religioso como tal de aquellos otros que, por ejemplo, fundan los conceptos de lo ético, de lo jurídico, de lo político o de lo económico. Ahora bien, nada es más problemático que una disociación semejante" (Derrida, 1996, p. 42). En el mismo sentido, Smart (2005, p. 222) argumenta que, al estudiar poblaciones reales no es viable identificar una frontera tajante que divida lo religioso de lo que no lo es.

En el contexto de las democracias contemporáneas para pensadores como Habermas (2002), Taylor (2007) o Mardones (2006), es necesario tener en cuenta los aspectos morales y religiosos que están intrínsecamente ligados a las decisiones políticas, considerando los valores últimos que están más allá de las acciones. Toda decisión política en el fondo y en última instancia se basa en concepciones de lo bueno y lo malo (Habermas, 2006), o de lo que es una "vida buena" (Mardones, 1996; Taylor, 2007), temas que hacen parte de los discursos religiosos.

Es por eso que, para Habermas (2010), es inevitable que, tarde o temprano, se le otorgue un espacio a los grupos religiosos en los debates públicos. De manera global, estas demandas ya se están evidenciando, como veremos más adelante. Berger (1999) o Casanova (1994) hacen notar que el surgimiento de movimientos político-religiosos en todo el mundo evidencia la relación entre la definición de las políticas y las propuestas de los grupos religiosos. Todas las sociedades y todas las propuestas de un ordenamiento social -es decir, todas las políticas- están basadas en "imaginarios sociales", los cuales, subraya Taylor (2007) están presentes tanto en movimientos sociales "seculares", como en movimientos "religiosos".

Para Habermas, es necesario reconocer la presencia de las religiones (institucionalizadas) en la esfera pública. El filósofo y sociólogo alemán plantea que, en el mundo contemporáneo, es inevitable y deseable que dichas religiones sean actores que participan en los debates públicos, haciendo aportes significativos, especialmente como voces de resistencia a las lógicas economicistas basadas únicamente en la acumulación de ganancias y la razón instrumental (Habermas, 2002). Su propuesta es post-secularista en la medida en que vivimos en sociedades que ya no pueden sostener el ideal secularista de un Estado que no reconoce los puntos de vista de los grupos religiosos. Este post-secularismo está asociado con el proceso de desprivatización de la religión, proponiendo nuevas perspectivas morales que enriquecen el debate político. De hecho, este reconocimiento del punto de vista de los grupos religiosos es coherente con los principios democráticos y pluralistas que la mayoría de Estados en el mundo acogen actualmente (Mardones, 2006).

Cuando se plantea la importancia de lo religioso en la conformación de las políticas públicas, no se está haciendo referencia a la idea según la cual las religiones tienen una importancia fundacional en las sociedades. No se pretende decir, entonces, que las religiones deben seguir teniendo un lugar en la política porque tuvieron (nótese el uso del tiempo pretérito) un rol fundamental en la constitución de las sociedades. Dicha propuesta preserva el prejuicio intelectual según el cual la religión es cosa del pasado.

2 Nótese que es fundamental hacer la distinción conceptual entre lo religioso y la religión institucionalizada eclesiástica. 
Tampoco se pretende decir que las religiones son fundamentales para preservar la identidad y la cohesión social de todas las sociedades, incluyendo las modernas. Si siguiéramos esa línea de raciocinio, necesariamente tendríamos que adherir a las ya superadas teorías de la secularización, en las que se demuestra que la religión, si bien importante, puede ser reemplazada por otras instituciones o esferas que cumplan las funciones fundacionales, identitarias o cohesionantes que tuvo la religión en las sociedades premodernas.

Desde "la paz de Westphalia" se ha asumido que las religiones no son las únicas instituciones capaces de dar identidad o cohesión a las sociedades (Beyer, 2013, p. 667). La "paz de Westphalia" se basa, precisamente, en que la pluralidad y las divisiones religiosas no conllevarán al desmoronamiento de las unidades políticas de la modernidad. Sabemos entonces que "religious boundaries were not simply isomorphic with political boundaries" (Beyer, 2013, p. 668). Desde entonces, los Estados modernos pueden imaginar la existencia de una pluralidad de religiones en sus territorios y no necesitan de una uniformidad religiosa para poder subsistir unificados.

Las relaciones que acabamos de ver entre religión y política no llevan a desechar completamente la teoría de la secularización. Sin embargo, siguiendo a Casanova (1994), es necesario aclarar que la teoría de la secularización está compuesta en realidad por 3 tesis diferentes: el declive de la religión, la diferenciación de la religión, y la privatización de la religión. Este análisis segmentado permite echar luces sobre aspectos fundamentales para comprender el lugar de la religión en la modernidad tardía.

La tesis del declive de la religión plantea que las religiones tienden a desaparecer a medida que avanza la modernización. Desde la llustración, la religión se considera como un conjunto de mentiras o ilusiones, un artificio creado por sacerdotes para dominar a las masas, o un vestigio del pasado condenado a morir. Estas ideas perduran hoy en un sector de la intelligentsia atea y "racional" que suele considerar que las creencias religiosas son producto de la ignorancia o del miedo de los creyentes, y que la educación moderna y "racional" puede acabar con esas creencias. La modernización, desde este punto de vista, es incompatible con la presencia de la religión.

Esta tesis ha sido contundentemente falseada por evidencias empíricas (Berger, 1999; Casanova, 2009). Suponer que el proceso de secularización conlleva el declive progresivo de las prácticas y creencias de tipo religioso, no es más que eso, una suposición que no está soportada en ninguna evidencia empírica general (Casanova, 1994, p. 17). Berger es enfático en afirmar que, a pesar de que la modernización ha seguido avanzando, hoy vivimos en un mundo tan religioso como hace siglos (Berger, 1999, p. 3). La tesis secularista no es pues una teoría corroborada, aunque fuese dominante en la sociología hasta hace unas décadas. Los apologistas del secularismo confundieron su ideal normativo (la religión debe acabarse) con una teoría científica que supuestamente daba cuenta de los hechos sociales (la religión se está acabando) (Casanova, 2009). Hoy se reconoce que los sujetos modernos, por más que vivan en sociedades estructuradas bajo el paradigma secularista que separa la religión y las demás esferas, pueden ser tan religiosos como los sujetos pre-modernos o no modernos (Taylor, 2007).

En cuanto a la tesis de la diferenciación, esta aun puede considerarse como válida, a condición de que se precisen sus términos. En efecto, cabe insistir que la diferenciación que la modernidad ilustrada enfatiza es la separación entre la religión institucionalizada (primeramente la Iglesia) y las demás "esferas". Por demás, es importante no confundir una tesis que constata un tipo de diferenciación entre sistemas funcionales, con la afirmación normativa (propia de la Ilustración) según la cual la alianza entre la Iglesia y el Estado es indebida, ya que las autoridades religiosas buscan mantener al pueblo ignorante para que este siga 
siendo oprimido y explotado (Casanova, 1994, p. 32)3. Quienes abogan por la necesidad de una diferenciación entre la religión y las demás esferas, especialmente la política, se basan principalmente en el ejemplo de la Iglesia y sus intereses cesaropapistas. "La iglesia católica se convirtió en la forma paradigmática de una religión publica antimoderna" (Casanova, 1994, p. 9), es decir, de la religión que, por pretender interferir en los asuntos públicos, era incompatible con principios de la modernidad.

Al distinguir la religión de la iglesia es posible entender que la supuesta incompatibilidad entre religión y modernidad (con su esfera política) no es más que una prescripción normativa de raigambre ilustrado que puede ser desmentida mediante un caso tan evidente como es el de la constitución de los Estados Unidos de Norteamérica. En ese país nunca se percibió la necesidad de acabar con la religión para poder instaurar una democracia. En los orígenes del país del norte no existía una Iglesia católica dominante (como en Europa y en América Latina) que buscaba dominar todas las esferas de la sociedad, una iglesia instalada en el poder y que no iba a permitir a ningún otro grupo o sector social imponerse o progresar. No existía, por lo tanto, la necesidad de acabar con la religión y abolir, como en la Francia de la laicidad, todo tipo de referencia a lo religioso en la esfera política. Este gran contra-ejemplo no puede ser considerado una especie de caso marginal dentro de la modernidad, ya que, como Casanova (2009) señala, Estados Unidos se convirtió en el país faro de la modernización y de la democratización. Si bien la llustración francesa fue anti-clerical y anti-cristiana, la Ilustración norteamericana claramente no lo fue.

Respecto a la tesis de la privatización de la religión, esta sostiene que, aunque la religión no tiene necesariamente que desaparecer, ella sí será relegada a la esfera de lo privado. Las personas pueden continuar teniendo creencias religiosas, pero estas no tendrán ninguna influencia en lo público o en las decisiones trascendentes de la sociedad en su conjunto. Como ya vimos, esta versión privatizada de la religión fue en parte promovida por la misma Reforma protestante, ya que ella insiste en la relación íntima del individuo con la divinidad, una relación individualizada que buscaba independizar al sujeto de las disposiciones comunitarias de la Iglesia (Beck, 2009).

Luckmann (1973) es uno de los autores más relacionados con esta tesis. Aunque equivocado en su generalización sobre aquella supuesta privatización de la religión en el futuro, el aporte de Luckman ha sido importante para que la sociología hubiera podido comenzar a estudiar aquello que él llamó "la religión invisible", es decir, la religión no institucionalizada. La sociología, en efecto, había ignorado demasiado lo religioso más allá de las iglesias. Era necesario, como dice Parker (2010), acabar con el enfoque "eclesiocéntrico" de nuestra disciplina. Donde se equivocó Luckmann fue al pensar que las instituciones religiosas tradicionales iban a ser progresivamente marginalizadas al ámbito de lo privado y, consecuentemente, su papel en la constitución de lo público terminaría siendo irrelevante. Autores como Casanova (1994) y Berger (1999) han demostrado que ello sencillamente no ocurrió de manera generalizada. Sin duda, algunas religiones institucionalizadas perdieron poder en ciertos contextos socio-históricos, lo que llevó a Weber a plantear la "eliminación del poder eclesiástico sobre la vida" (Weber, 1999, p. 28), pero las expresiones eclesiales no agotan la presencia de lo religioso en la vida social contemporánea.

De otra parte, aunque algunos autores contemporáneos siguen sosteniendo la tesis de la privatización (Bruce, 2002), generalmente lo hacen porque no perciben el carácter colectivo ni la incidencia en lo público de las nuevas manifestaciones religiosas. No obstante, planteamientos como los de Bellah (1967) a propósito de una "religión civil", o la categoría de "religión implícita" propuesta por Bailey (2010), abrieron en el camino para investigaciones recientes donde se demuestra que incluso lo que actualmente es llamado "espiritualidad" - una forma de religiosidad moderna radicalmente des institucionalizada, individualista y

3 Casanova retoma los escritos de autores como Voltaire, Montesquieu y Rousseau. 
anti-eclesial (Heelas y Woodhead, 2005)- constituye un fenómeno claramente colectivo y que tiene efectos políticos puesto que incide en la movilización de individuos pertenecientes a sectores dominantes de las sociedades modernas, incluyendo las latinoamericanas (Frigerio, 2016; Sarrazin, 2017).

\section{Retorno a Durkheim y lo sagrado más allá de las religiones}

Hemos notado que la pregunta por el carácter diferenciado o no de la religión depende de la definición que se provea de dicho concepto. Tan importante definición, sin embargo, no es en absoluto clara ni consensual en las ciencias sociales, situación que ha provocado no pocos malentendidos y confusiones (Sarrazin, 2018). Si entendemos la religión bajo su manifestación institucional, parece evidente que sí existe una diferenciación entre ella y otras esferas como la política. Sin embargo, el enfoque eclesiocéntrico no es el único posible. De hecho, si persistimos en la concepción de religión únicamente bajo su forma institucionalizada, las tesis de la privatización y el declive de la esa forma de religión podrían eventualmente ser ciertas, aunque autores como Berger, Casanova o Taylor señalan que no hay todavía ninguna evidencia de ello.

Pero, más allá de las "religiones públicas" o de la "post-secularidad", existen otras maneras en que lo religioso se ha expresado. Gauchet, quien considera (a diferencia de Berger o Habermas) que la religión institucionalizada está condenada a morir, reconoce al mismo tiempo que el hombre moderno "continuará viviendo experiencias de tipo religioso sin identificarlas de manera forzosa como tales" (Gauchet, 2005, p. 294). Aunque las religiones institucionalizadas llegaran a perder toda relevancia en la estructuración de la sociedad futura o aun si viéramos la "eliminación del poder eclesiástico sobre la vida", como dijo Weber, es indudable que lo religioso se ha encontrado hasta ahora en todas las sociedades, incluidas las más modernas, sólo que en estas últimas se ha venido transformando y diversificando (Hervieu-Léger, 2005). Se constata entonces la "supervivencia de lo religioso en el seno de un mundo sin religión" (Gauchet, 2005, p. 289). En palabras de Taylor, el "marco de trascendencia" mediante el cual los sujetos toman las decisiones que consideran más importantes en sus vidas, persiste sin dar signos de debilitamiento, aunque vivamos en una "era secular" (Taylor, 2007). Este es "un vasto dominio de la religiosidad que se ignora, lo que podría llamarse ‘lo religioso sin religión', sin atadura a una tradición o a una formación explícita” (Gauchet, 2005, p. 295).

En la tarea de identificar "lo religioso sin religión" o la religión más allá de las iglesias, el aporte de Durkheim es de particular utilidad. Como señala Prades (1998, p. 29), "Durkheim insiste en la naturaleza religiosa de los intereses [...] colectivos", anticipando así que el Estado y la Nación podían contener aquella "naturaleza religiosa" e inspirando conceptos posteriores como el de "religión civil" (Bellah, 1967). A diferencia de Weber, Durkheim se interesa por todo tipo de expresión religiosa, institucionalizada o no (Prades, 1998, p. 45). En efecto, Durkheim se preocupó por el equivalente secular de la religión, o cómo se expresa lo religioso en lo secular. De esta manera podemos integrar el pensamiento de Durkheim a un campo epistemológico nuevo, el de las transformaciones de la religión una "era secular".

Es por eso que Durkheim se interesó por los "fenómenos religiosos" por fuera de la religión institucionalizada. Antes de publicar "Las Formas Elementales de la Vida Religiosa", el autor había escrito un artículo titulado justamente "De la définition des phénomènes religieux" (Durkheim, 1899). En él aclara, primeramente, que lo religioso no se limita a las ideas de la divinidad o de lo sobrenatural, ya que hay religiones en las que estas nociones no existen. Asimismo, en uno de sus cursos en La Sorbona, afirma que "las ideas de dioses o seres espirituales no agotan la vida religiosa" (citado por Prades, 1998, p. 139), momento en el cual rechaza las tesis animistas sobre el origen de la religión propuestas por Tylor y Spencer. 
Por otro lado, no se debe confundir, aclara Durkheim (1899), la divinidad con lo sagrado, ya que hay distintos tipos de "cosas" que también pueden ser sagradas, como templos o personas. A lo anterior se añade que los fenómenos religiosos están compuestos por creencias "obligatorias" y las prácticas que se desprenden de ellas (Durkheim, 1899, p. 18). Las creencias obligatorias son aquellas que los miembros de la sociedad no pueden contradecir y sobre las que no cabe la menor duda; son "dogmas", "mitos" o "estados mentales" (Durkheim, 1899, p. 16) que se imponen al individuo como una evidencia indiscutible, son formas de pensar incuestionables, así como lo sagrado es incuestionable.

Pero considerar seriamente las transformaciones de lo religioso y su presencia en lo "secular" implica un ambicioso proyecto que requiere precisar una categoría analítica operacional que permita, como lo quiere Durkheim, identificar lo religioso allí donde esté, incluso por fuera de lo que convencionalmente se conoce como la religión. Dicha categoría es lo sagrado.

Lo sagrado es lo que está presente tanto en las diferentes religiones institucionalizadas como en todo tipo de fenómeno religioso. Lo sagrado se define por su carácter excepcional que lo distingue radicalmente de lo profano, en una oposición tajante y única, se trata de una "heterogeneidad radical". Lo sagrado es completamente Otro con respecto a lo profano (Durkheim, 1982, p. 34). A pesar de semejante separación entre lo sagrado y lo profano, esto no quiere decir, para Durkheim, que no se puedan presentar relaciones dinámicas entre los dos polos. Así como hay ritos cuyo fin es prohibir la confusión entre lo sagrado y lo profano, hay ritos que buscan poner al fiel en relación con la cosa sagrada (Prades, 1998, p. 141). Incluso, reconoce Durkheim, hay casos en los que un ser puede pasar de lo sagrado a lo profano, o viceversa, aunque este cambio nunca sea simple ni anodino (Durkheim, 1982, p. 35). Al hablar de este cambio posible, Durkheim (1982, p. 33) nos permite pensar en procesos de sacralización por lo que, dependiendo del contexto socio-histórico dado, "cualquier cosa puede ser sagrada": árboles o rocas, ritos, palabras, gestos, etc.

En su célebre definición de religión, Durkheim (1982, p. 42) afirma que las cosas sagradas son "interdictas". Esta palabra, presente en la traducción al castellano de la obra del clásico, no es del todo acertada. La palabra "vedadas" sería más apropiada como equivalente del término "interdites" (del verbo "interdire") presente en la versión original en francés (Durkheim, 1960, p. 65). Es importante reconocer que el verbo francés "interdire" está emparentado con el verbo "défendre", y es necesario recurrir a otras partes de la obra de Durkheim para comprender mejor el concepto utilizado. "Las cosas sagradas son aquellas que las prohibiciones protegen y aíslan" (1982, p. 36), es decir, que las normas sociales defienden lo sagrado de posibles vulneraciones o violaciones. Al enfatizar su separación, se infiere que las cosas sagradas conforman esa categoría absolutamente especial que no se debe alterar ni cuestionar. Las creencias relativas a las cosas sagradas son obligatorias Adicionalmente, explica el autor, las cosas sagradas son altamente valoradas, deben tener una posición elevada dentro de la jerarquía de los seres (1982, p. 33). Las cosas sagradas "corrientemente son consideradas como superiores en dignidad y poder a las cosas profanas, y particularmente al hombre, en el caso de que éste no sea más que un hombre y, en sí mismo, no esté sacralizado" (Durkheim 1982, p. 33).4

Para Durkheim, ciertas "cosas" comúnmente consideradas como propias del ámbito de la esfera política secular pueden ser sacralizadas en la modernidad. "La patrie, la Révolution française [...], etc., sont pour nous des choses sacrées auxquelles nous ne permettons pas qu'on touche. L'opinion publique ne tolère pas volontiers qu'on conteste la supériorité morale de la démocratie, la réalité du progrès, l'idée d'égalité,

4 Es importante, no obstante, distinguir la simple superioridad de la sacralidad. "Una diferenciación puramente jerárquica es un criterio a la vez demasiado general y demasiado impreciso" (1982, p. 34). 
de même que le chrétien ne laisse pas mettre en discussion ses dogmes fondamentaux" (1899, p. 17-18)5. Refiriéndose a ciertos rituales seculares que se dan en la solemnidad de los actos públicos del Estado, Durkheim añade que "los hombres no se equivocan cuando piensan que en esos momentos vive algo más fuerte de lo cual dependen, que los eleva por encima de sí mismos, los ennoblece, los santifica" (Curso en La Sorbona, citado por Prades, 1998, p. 141). Esto es particularmente útil para entender que distintos rituales en la modernidad tardía evocan aquel tipo de sentimientos religiosos en quienes los practican. Eso "más fuerte", "que los eleva por encima de sí mismos", no es, por supuesto, una fuerza no humana y sobrenatural. "Eso" es una construcción social que el individuo ha interiorizado y que lo "eleva" porque culturalmente representa algo superior e incontestable.

\section{Lo sagrado en la política actual}

Al plantear que la patria, la democracia, la idea de igualdad o el progreso son sacralizados en la modernidad, Durkheim permite ver claramente que hay un elemento religioso fundamental en el lenguaje y en el sistema de valores de la esfera política moderna.

Una "cosa sagrada" que Durkheim identificó como parte de las transformaciones de lo religioso en la modernidad, es el individuo. La individualización es relacionada con la diferenciación, no la de esferas, sino la de los roles. En "Las Reglas del Método Sociológico", Durkheim (1997) plantea que la sociedad moderna se divide en grupos cada vez más diferenciados de acuerdo con las funciones que cumplen y el tipo de actividades que desempeñan. Lo anterior hace que los individuos amplíen sus diferencias entre sí, convirtiéndose en regla el hecho de ser, cada vez más, una persona particular. El individualismo que se reproduce en la modernidad siguió siendo una preocupación de Durkheim a lo largo de los años. En un texto posterior, el sociólogo afirma que ese individualismo (que no se debe confundir con el egoísmo de los economistas utilitaristas) es profesado desde el siglo XVIII por una buena parte de los grandes pensadores, como Rousseau y Kant, y además ha influido en la Declaración de los Derechos del Hombre (Durkheim, 1898, p. 5). Se trata de la apoteosis del bienestar y el interés personales (Durkheim, 1898, p. 6). El sujeto moderno tiene el deber de fijarse en lo que le interesa como individuo, debe preocuparse por lo que concierne su individualidad (Durkheim, 1898, p. 6). "Esta persona humana, cuya definición es la base sobre el cual se erigen las distinciones entre lo bueno y lo malo, es considerada como sagrada. [...] Tal moral no es entonces simplemente una disciplina higiénica o una sabia economía de la existencia; es una religión en la cual el hombre es, al mismo tiempo, el fiel y el Dios" (Durkheim, 1898, p. 6. Énfasis añadido), donde el individuo se rinde culto a sí mismo (Durkheim, 1898, p. 9). Así, el individualismo puede entenderse como una forma de religión transmutada en la modernidad, donde el yo se ha convertido en una cosa sagrada que se venera y cuya existencia, carácter único y valor supremo no se cuestionan.

Puesto que le individuo es sacralizado, los "derechos del individuo" adquieren también un carácter incuestionable y se ubican por encima de cualquier otro criterio normativo. En el fondo, subraya Durkheim, estamos hablando del "liberalismo", doctrina en la que el culto a la persona humana, sus derechos y sus libertades, son una idea central. Las políticas que se definen desde el liberalismo se basan en una "glorificación del individuo", se trata de una ideología política que "tiene como primer dogma la autonomía de la razón [...] y la libertad de consciencia como la primera de las libertades" (Durkheim, 1898, p. 9).

5 "La patria, la Revolución Francesa [...], etc., son cosas sagradas para nosotros, las cuales no permitimos que sean tocadas. La opinión pública no tolera fácilmente que se cuestione la superioridad moral de la democracia, la realidad del progreso, la idea de igualdad, así como los cristianos no permiten que se cuestionen sus dogmas fundamentales". (Traducción del autor). 
El relacionar el individualismo con la esfera política es una idea corroborada por otros autores posteriores a Durkheim, y no necesariamente funcionalistas. Rosanvallon, por ejemplo, hace notar que la noción de ciudadano como individuo libre y autónomo es indispensable para legitimar el modelo político democrático. No se concibe una democracia moderna sin esa ontología liberal en la que el individuo, como ser separado y único, legitima con su voto una forma de gobierno. En otras sociedades "aun cuando era el pueblo quien era convocado, se le concebía como un cuerpo unificado, como una totalidad y no como una yuxtaposición de individuos" (Rosanvallon, 1992, p. 31). En el mismo sentido, Poulantzas señala que el funcionamiento del Estado capitalista y sus instituciones se basan en la atomización del cuerpo político, "en eso que se designa como 'individuos', personas jurídico-políticas y sujetos de libertades" (Poulantzas, 2005, p. 70). Así, la política moderna es un proyecto que marca una ruptura con otras formas políticas donde no se pensaba la comunidad en términos de un conjunto de individuos separados, libres, autónomos y con derechos.

Turner (1997, p. 208), por su parte, considera que el individualismo y su doctrina de los derechos individuales se expresa en "toda una gama de formas religiosas, políticas, económicas y jurídicas". Efectivamente, el individualismo se expresa en la política al influir en las decisiones que afectan lo público y que ponen por delante el derecho de los individuos a ejercer su libertad. Esto se observa actualmente en los debates políticos en torno a la libertad de consciencia y de culto, 6 al aborto, o en las políticas educativas basadas en el concepto de "libre desarrollo de la personalidad", por mencionar solo algunos casos. Turner corrobora que estas posiciones políticas trazan sus orígenes en el mismo pensamiento cristiano protestante. El protestantismo reemplazó los "métodos sacramentales de expiación" por la noción de "responsabilidad individual para la acción", responsabilidad que se trasladó al terreno de lo político y lo legal más tarde en la modernidad (Turner, 1997, p. 208).

La propuesta de Durkheim sobre la relación entre lo sagrado y la política es criticada de parte de quienes consideran que dicha relación quizás era válida para la modernidad temprana y el nacimiento del Estado Nación, pero no lo sería actualmente en las democracias pluralistas (Rosati, 2009). En estas democracias aparentemente todo se somete al debate y puede ser cuestionando por diferentes puntos de vista, lo cual sería contrario a la existencia de ciertas nociones colectivas de lo sagrado que logran imponerse en la esfera política. Sin embargo, independientemente de la pluralidad de puntos de vista, sigue siendo sagrada -y colectivamente legitimada- la idea de una sociedad compuesta por individuos libres y autónomos, tal como lo dijo Durkheim. De hecho, la valoración de la diversidad que se plantea en el pluralismo como ideología política (Sarrazin, 2016), proviene de la valoración extrema de la libertad individual, en particular, la libertad de opinión y de conciencia7, lo cual implica la posibilidad del individuo para diferir y tener opiniones distintas a las de los demás. Lo que es importante notar acá es que esa "religión" del liberalismo y sus sacralidades no se presenta como un conjunto de dictámenes que obligan a las personas a actuar en contra de sus deseos. Se trata de una ontología (el ser humano es un individuo separado, libre, autónomo, sujeto de derechos, etc.) que genera normatividades (Sarrazin, 2015) y que, en consecuencia, fundamenta decisiones políticas. La sacralidad del individuo es parte de tal ontología, y el sistema político, por más pluralista que sea, basa sus reglas sobre esa sacralidad. Cierto es que en las sociedades modernas (y no solo en ellas, ya lo había dicho Durkheim a propósito de las sociedades "primitivas") existen sectores sociales que compiten por imponer diferentes nociones de lo sagrado. La sacralización es también un terreno en

6 La presencia de la ideología liberal en altas instancias gubernamentales es ejemplificada en las decisiones tomadas por la Corte Constitucional de Colombia en los años 1990 (Sarrazin y Redondo, 2018).

7 Esta libertad está en el corazón de la Reforma Protestante y parte de la libertad religiosa. Como recuerda Herrero (2017, p. 390), citando a Carl Schmitt, "El primer derecho individual, en el sentido del ordenamiento social burgués fue la libertad religiosa". 
disputa y puede cambiar a lo largo de la historia, pero esto no niega que, en un momento dado, las estructuras políticas dominantes estén basadas en ciertas nociones particulares de lo sagrado; tal es el caso del pluralismo que se impone hoy en día en las democracias liberales.

Bajo el liberalismo, la individualidad, con su libertad y el derecho a diferir que le acompañan, debe ser protegida a toda costa. Por eso, incluso si nos declaramos pluralistas, existen ciertas ideologías y posiciones políticas que no se aceptan y que son clasificadas bajo términos con connotaciones negativas como "fundamentalismo" o "autoritarismo". Scobie (2002, p. 298) señala que la protección de la individualidad que encontramos en el liberalismo hace que cualquier líder político que se plantee como una autoridad por encima de las libertades individuales, será rápidamente deslegitimado y será combatido con diferentes tipos de oposición como las manifestaciones pacíficas, la denuncia pública o la rebelión. Semejante rechazo colectivo deja notar que sí hay, en efecto, principios que el liberalismo pluralista aísla, defiende y no permite que se "profanen", tal como ocurre con las "cosas sagradas".

\section{Conclusiones}

Para Durkheim, los símbolos, los ritos, los sacerdotes o los templos no son más que elementos secundarios de las religiones. Lo esencial de los "fenómenos religiosos" son las creencias y prácticas relativas a "cosas sagradas", es decir, "cosas" especiales que no deben ser alteradas, que no pueden ser cuestionadas, y cuyo valor es inconmensurable. Ante las profundas transformaciones de las religiones, haber planteado aquella noción esencial de lo religioso nos permite identificar las nuevas formas de religión en una "era secular". Esa religión moderna es el "culto a la persona humana", un individualismo que fundamenta la política democrática liberal. Lejos de destruir las sociedades disgregándolas en un conjunto informe de átomos dispares, el individualismo es un elemento común que hace que las personas compartan ideales y metas, reconfigurando los vínculos sociales y definiendo sistemas políticos como el que conocemos actualmente.

Al señalar la presencia de lo religioso en la política, no debemos limitarnos a hacer notar las similitudes que pueden existir entre las estructuras eclesiásticas y las estructuras políticas modernas, o la participación que pueden tener algunas religiones reconocidas en las esferas estatales, tal como lo señalan importantes autores como Schmitt, Habermas, Berger o Casanova. La argumentación presentada acá va más allá, al señalar que las "cosas sagradas" que caracterizan toda religión y todo fenómeno religioso están también presentes en la esfera política, y no como un influjo exterior, sino como uno de sus componentes esenciales. No se trata entonces de redescubrir elementos religiosos pasados que aún se encuentran en la política moderna, ni de reconocer la participación de las iglesias en una esfera que les es ajena, sino de identificar las cosas sagradas que hacen parte del lenguaje y de los valores de esta esfera "secular".

Pareciera paradójico recurrir a Durkheim para cuestionar la teoría de la diferenciación, cuando el funcionalismo es considerado comúnmente como una escuela sociológica que apoya dicha teoría. Sin embargo, el cuestionamiento presentado acá no invalida completamente las teorías de la secularización y la diferenciación; el aporte consiste en dejar en claro que sólo hay diferenciación y secularización en lo que respecta a una cierta definición de religión. El concepto de iglesia se convirtió, desde la Edad Media, en sinónimo de la religión. Esa religión-iglesia claramente institucionalizada desde tiempos pre-modernos ha sido efectivamente separada de otras esferas que devinieron dominantes con el paso del tiempo. Es así que la modernidad crea, sin duda, una diferenciación entre lo que tradicional, convencional e institucionaImente se conoce como "la religión" y (más tarde) "las religiones". Pero la religión como categoría analítica de las ciencias sociales no se agota en las iglesias, y lo religioso en la modernidad no necesariamente obe- 
dece a los modelos de religión que fueron estudiados en siglos pasados.

Es por eso que las teorías de la diferenciación y la secularización encuentran un límite al reconocer la presencia de lo religioso en lo secular, reconocimiento que es posible mediante el marco teórico y conceptual propuesto por Durkheim. La "era secular", sin duda, confirma la muerte de Dios en las esferas que la misma modernidad crea, pero en ellas viven otros dioses u otras "cosas sagradas", tal y como ocurre en las religiones tradicionales. Está claro que existen esferas diferenciadas en la modernidad, por lo que podemos hablar de esferas religiosas y esferas políticas, pero eso no debe confundirse con la afirmación según la cual la religión y la política -en términos generales- son efectivamente dos esferas diferenciadas en la modernidad. Aquel principio religioso que Durkheim identificó mediante la categoría de lo sagrado no se circunscribe ni se limita a una esfera en particular.

\section{Referencia Bibliográfica}

Asad, T. (1993). Genealogies of Religion. Discipline and Reasons of Power in Christianity and Islam. Baltimore: Johns Hopkins University Press.

Bailey, E. (2010). Implicit Religion. Religion, 40, 271-278. DOI: 10.1016/j.religion.2010.07.002.

Beck, U. (2009). El Dios personal. La individualización de la religión y el "espíritu" del cosmopolitismo. Barcelona: Paidós.

Bellah, R. (1967). Civil religion in America. Daedalus, 96(1), 1-21.

Beyer, P. (1999). Religión, problemas residuales y diferenciación funcional: una relación ambigua. Sociológica, 14(41), 199-209.

Beyer, P. (2013). Questioning the secular/religious divide in a post-Westphalian world. International Sociology, 28(6), 663-679. DOI: 10.1177/0268580913507070.

Blancarte, R. (2015). ¿Por qué la religión "regresó" a la esfera pública en un mundo secularizado?. Estudios Sociológicos, 33(99), 659-673.

Bruce, S. (2002). God is Dead: Secularisation in the West. Oxford: Blackwell.

Casanova, J. (1994). Public Religions in the Modern World. Chicago: University of Chicago Press.

Casanova, J. (2009). The secular and secularisms. Social Research, 76(4), 1049-1066.

Derrida, J. (1996). Post-scriptum. En J. Derrida \& G. Vattimo (Eds.). La religión (pp. 37-106). Madrid: PPC.

Durkheim, É. (1898). L'individualisme et les intellectuels. Revue Bleue, 4(10), 7-13.

Durkheim, É. (1899). De la définition des phénomènes religieux. Année Sociologique, 2, 1-28.

Durkheim, É. (1960). Les Formes Élémentaires de la Vie Religieuse. Paris: Presses Universitaires de France.

Durkheim, É. (1982). Las formas elementales de la vida religiosa. Madrid: Akal.

Durkheim, É. (1997). Las Reglas del Método Sociológico. México D.F.: Fondo de Cultura Económica.

Durkheim, É. (2001). La División del Trabajo Social. Madrid: Akal.

Eliade, M. (1999). Historia de las Creencias y de las Ideas Religiosas. Barcelona: Herder.

Frigerio, A. (2016). La ¿'nueva'? Espiritualidad: Ontología, epistemología y sociología de un concepto controvertido. Ciencias Sociales y Religión/Ciências Sociais e Religião,18(24), 209-231.

Gauchet, M. (2005). El Desencantamiento del Mundo. Una Historia Política de la Religión. Granada: Trotta.

Habermas, J. (2002). Religion and Rationality: Essays on Reason, God, and Modernity. Cambridge, MA: MIT Press. 
Habermas, J. (2006). Religion in the Public Sphere. European Journal of Philosophy, 14(1), 1-25.

Habermas, J. (2010). An Awareness of What is Missing: Faith and Reason in a Post-secular Age. Cambridge: Polity Press.

Heelas, P. \& Woodhead, L. (2005). The Spiritual Revolution: Why Religion is Giving Way to Spirituality. London: Wiley-Blackwell.

Herrero, M. (2017). Teología política y representación en el pensamiento de Carl Schmitt. Revista de Filosofía Aurora, 29(47), 377-403. DOI: 10.7213/1980-5934.29.047.DS01

Luckmann, T. (1973). La Religión Invisible. Salamanca: Sígueme.

Luhmann, N. (1985). Society, Meaning, Religion: Based on Self-Reference. Sociological Analysis, 46(1), 5-20.

Luhmann, N. (2009). Sociología de la Religión. México: Herder.

Mardones, J. M. (1996). De la secularización a la desinstitucionalización religiosa. Política y Sociedad, 22, 123-135.

Mardones, J. M. (2006). Religión y Democracia. Cuestiones Teológicas, 33(79), 9-26.

Marx, K. (2010). Crítica de la Filosofía del Estado de Hegel. Madrid: Editorial Biblioteca Nueva.

Parker, C. (2010). El eclesiocentrismo en los clásicos de la sociología occidental. En D. Gutiérrez (Comp.). Religiosidades y creencias contemporáneas. Diversidad de lo simbólico en el mundo actual (p.p. 47-69). Zinacantepec: El Colegio Mexiquense.

Poulantzas, N. (2005). Estado, Poder y Socialismo. Madrid: Siglo XXI.

Prades, J. (1998). Lo Sagrado. Del Mundo Arcaico a la Modernidad. Barcelona: Península.

Rosati, M. (2009). Ritual and the Sacred: A Neo-Durkheimian Analysis of Politics, Religion and the Self. New York: Routledge.

Sarrazin, J. P. (2015). Aportes para el Estudio Empírico de los Valores y su Difusión Social. Revista de Antropología y Sociología: Virajes, 17(1), 135-158.

Sarrazin, J. P. (2016). Avatares del Pluralismo. Usos y Abusos del Concepto de Diversidad Cultural en Medios Institucionales. Principia luris, 13(26), 55-73.

Sarrazin, J. P. (2017). ¿Guiados por Dios o por Sí Mismos? Estudio comparativo entre adeptos a las espiritualidades alternativas y adeptos a las iglesias evangélicas. Cuestiones Teológicas, 44(102), 373-396.

Sarrazin, J. P. (2018). Religión: ¿sabemos de lo que estamos hablando? Examen sobre la viabilidad de una categoría analítica para las ciencias sociales. Criterio Libre, 16(29), 67-84.

Sarrazin, J. P. y Redondo, S. P. (2018). Indígenas Evangélicos y Diversidad Cultural. Análisis de una Problemática Multiculturalista. Revista de Derecho, 49, 203-228.

Schmitt, C. (2000). Catolicismo y Forma Política. Madrid: Tecnos.

Scobie, G. (2002). The Religion of Politics. En E. Bailey (Ed.). The Secular Quest for Meaning in Life : Denton Papers in Implicit Religion (pp. 295-308). Queenston: Edwin Mellen Press.

Smart, N. (2005). Within and without religion. En R. McCutcheon (Ed.). The Insider/Outsider Problem in the Study of Religion (pp. 221-234). New York: Continuum.

Tschannen, O. (1991). The Secularization Paradigm: A Systematization. Journal for the Scientific Study of Religion, 30(4), 395-415. DOI: 10.2307/1387276.

Turner, B. (1997). La Religión y la Teoría Social. México: Fondo de Cultura Económica.

Weber, M. (1978). Sociología de la Religión. Buenos Aires: Pléyade.

Weber, M. (1999). La Ética Protestante y el Espíritu del Capitalismo. Barcelona: Península. 
